\title{
Prevalence and Sex Distribution of Temporomandibular Disorder and Their Association with Anxiety and Depression in Indian Medical University Students
}

\author{
Kaberi Majumder ${ }^{1}$, Shalender Sharma ${ }^{2 *}$, Dayashankara Rao JK ${ }^{2}$, Vijay Siwach ${ }^{2}$, \\ Varun Arya², Sunil Gulia ${ }^{2}$ \\ ${ }^{1}$ Department of Orthodontics, SGT Dental College, Gurgaon, India \\ ${ }^{2}$ Department of Oral and Maxillofacial Surgery, SGT Dental College, Gurgaon, India \\ Email: sharma.shalender@rediffmail.com
}

Received 17 July 2015; accepted 16 August 2015; published 19 August 2015

Copyright (C) 2015 by authors and Scientific Research Publishing Inc.

This work is licensed under the Creative Commons Attribution International License (CC BY). http://creativecommons.org/licenses/by/4.0/

CC)

\begin{abstract}
Objectives: The term TMD refers to a group of disorders characterized by pain in the temporomandibular joint and associated structures. The aim of this study was designed to evaluate prevalence, severity and sex distribution of sign and symptoms of TMD and to evaluate their relation with anxiety and depression among the students. Material and Methods: A total of 1000 university students were enrolled in the study (550 females; 450 males), with ages ranged between 18 and 28 years. Helkimo anamnestic index (Ai) and clinical dysfunction index (Di) were used to determine symptoms and signs respectively. For the association of TMD with anxiety and depression, HAD (Hospital Anxiety and Depression) scale was used. Results showed that prevalence of one or more symptoms of TMD was $27.7 \%$, while the prevalence of one or more signs of TMD was $64.4 \%$ which was mild in severity. Mild anamnestic symptoms (AiI) were found in $19.8 \%$ and severe symptoms (AiII) were found in 7.6\%, while mild clinical sign (DiI), moderate clinical (DiII) and severe clinical sign (DiIII) were found in $49.7 \%, 12.2 \%$ and $2.4 \%$ respectively. Statistically there was no gender difference in these two scales. Regarding the association between TMD with anxiety and depression, 206 of the 311 students $(66.2 \%)$ with TMD symptoms also had signs of anxiety and depression $(P<0.001)$. Conclusion: These findings confirmed that students had high prevalence of TMD which was significantly associated with anxiety and depression.
\end{abstract}

\section{Keywords}

TMD, Helkimo Index, HAD Scale, Anxiety

\footnotetext{
${ }^{*}$ Corresponding author.
}

How to cite this paper: Majumder, K., Sharma, S., JK, D.R., Siwach, V., Arya, V. and Gulia, S. (2015) Prevalence and Sex Distribution of Temporomandibular Disorder and Their Association with Anxiety and Depression in Indian Medical University Students. International Journal of Clinical Medicine, 6, 570-578. http://dx.doi.org/10.4236/ijcm.2015.68076 


\section{Introduction}

Temporomandibular joint disorders (TMD) are a group of conditions that cause pain and dysfunction in the jaw joint and the muscles that control jaw movement. Bell suggested the term temporomandibular disorders. The wide variety of terms used has contributed to the great amount of confusion that exists in this already complicated field. Therefore, the American Dental Association has adopted the term temporomandibular disorders. The movement of the mandible needs coordination among them to maximize function and minimize the damage to surrounding structures [1].

It has been well established, by means of epidemiological studies in which signs and symptoms of TMDs are common in adults of all ages [2]. Reports have shown that signs and symptoms of temporomandibular disorder (TMD) increase with age [3]; however, other studies have shown a decrease in symptoms with increasing age [4]. Over a 20-year period, investigations on TMD have revealed predominately mild signs and symptoms already present in childhood. An increase in symptoms occurs until young adulthood, after which they level out [5]. The concept of TMD may be attributable to specific genes that are inheritable.

There is some evidence to suggest that anxiety, stress, and other emotional disturbances may exacerbate TMDs, especially in patients who clinically experience chronic pain. Nevertheless, the cause of the signs and symptoms of TMDs is not clearly understood and various opinions on their etiology have been offered [6].

Evidence indicates that myofascial pain and functional somatic syndromes such as fibromyalgia and chronic fatigue syndrome are comorbidities of the muscular pain that may be due to psychosocial factors. The manifestations of myofascial pain and discomfort coincide with moments of tension and stress, which causes muscular hyperactivity, and this tension can lead to parafunctional habits. Thus, psychosocial factors such as anxiety, stress, and depression might be important in the pathogenesis of TMD [7].

It is evident from the numerous epidemiologic studies on the occurrence of temporomandibular disorders that signs of temporomandibular disorders appear in about $60 \%-70 \%$ of the general population and yet only about one in four people with signs are actually aware of or report any symptoms [8].

The frequency of severe disorders that are accompanied by headache and facial pain characterized by urgent need of treatment is $1 \%-2 \%$ in children, about $5 \%$ in adolescents and $5 \%-12 \%$ in adults [9].

In epidemiological studies of TMD, Helkimo found that prevalence was between $12 \%$ and $57 \%$ for anamnestic symptoms and between $28 \%$ and $88 \%$ for clinical signs [10]. In Asia, Shiau [11] reported that $43 \%$ of Taiwanese university students had a prevalence of one or more signs of TMD. Jagger [12] found that more than $19 \%$ had anamnestic symptoms and that over 36\% showed clinical sign in university students. The lack of standardized criteria in the evaluation of TMD, however, makes comparison among different studies difficult. This problem was addressed by Helkimo [13] in 1974 and it was the basis for the development of his anamnestic (reported) and clinical dysfunction index which probably still remained the most widely applied system in epidemiological studies of TMD.

The aim of this study was to estimate the prevalence of TMD in SGT university students and to evaluate its association with anxiety and depression.

\section{Material and Methods}

\subsection{Study Design}

Sample consisted of 1000 students from five different colleges of SGT University. Only those students were enrolled in the study who signed a consent form agreeing to participate in the study. This study was approved by the SGT University IRB.

Out of 1000 students, 550 were females and 450 were males. Age ranged between 18 to 28 years with mean age of 23.4 years. The study population was students of the following institutions: SGT Dental College, SGT Medical College, SGT College of Pharmacy, SGT College of Physiotherapy and SGT College of Nursing. All students who agreed to participate were eligible for inclusion regardless of age or sex.

For evaluating the prevalence of severity and sex distribution of TMD Helkimo anamnestic dysfunction index was the instrument of choice. For evaluating the association of TMD symptoms with anxiety and depression Hospital Anxiety and Depression (HAD) scale was used.

\subsection{Data Collection}

Helkimo anamnestic index was one of the first instruments to be confirmed as reliable in identifying TMD sign 
and symptoms [14]. For the assessment of symptoms this index was classified into three grades;

(Ai0) denotes complete absence of subjective symptoms of dysfunctions of the masticatory system. (AiI) denotes mild symptoms; one or more of the following symptoms were reported in anamnesis: joint sound, feeling of fatigue, feeling of stiffness of the jaws on awaking. (AiII) denotes severe symptoms of dysfunction; one or more of the following symptoms were reported in anamnesis: difficulty in opening the mouth widely, locking, subluxation, pain on movement of the mandible, facial and jaw pain, pain and tiredness on chewing.

For evaluating the signs of TMD the masticatory system was examined in the following systematic way according to Helkimo.

Clinical examination include Measurements of maximal opening capacity, overbite and over jet, examination of occlusion, examination of impaired TMJ function which include clicking, crepitation, deviation, locking, luxation, examination of masticatory muscle pain or tenderness. The severity of the clinical signs was determined according to clinical dysfunction index by Helkimo. The severity of the clinical signs according to the scores was classified into four dysfunction groups; each group was given an index value as follows: $(\mathrm{Di} 0)=$ Dysfunction group $0=0$ point $=$ clinically free. $(\mathrm{DiI})=$ Dysfunction group $1=1-4$ points $=$ mild $(\mathrm{DiII})=$ Dysfunction group $2=5-9$ points $=$ moderated. $($ DiIII $)=$ Dysfunction group $3=10-25$ points $=$ sever dysfunction.

HAD scale was used to identify and measure the intensity of anxiety and depression in non psychiatric environments, as in the present population, and has been applied to this type of population in several previous studies [15]. The scale consists of 14 items divided into two scales. Seven items measure anxiety (HADS-A), and seven measure depression (HADS-D). Thus, the concepts of anxiety and depression are separated [16].

To complete the questionnaire, the participant selects the answer choice that is closest to what he/she felt during the previous week. Each item is scored from 0 to 3, depending on the response, and the maximum score is 21 points for each scale. In both scales a score of $0-7$ indicates absence of anxiety or depression, a score of 8 10 indicates possible anxiety or depression, and a score of 11 or higher indicates presence of anxiety or depression [15] [16]. Thus, an individual could have no, either, or both anxiety and depression. Several studies, in a wide variety of clinical populations, found that HAD had good sensitivity, specificity, and internal consistency in assessing anxiety and depression symptoms [16].

\subsection{Statistics}

The chi-square test of independence was used to evaluate prevalence of TMD with sex and its association with anxiety and depression. To ensure the applicability of the chi-square test of independence, TMD was classified as absent and present (which included mild, moderate, and severe TMD). For presence of anxiety or depression, only two groups were considered: absence of anxiety and depression versus presence of anxiety or depression (which included individuals classified as having anxiety or depression and those with possible anxiety or depression).

\section{Results}

The distribution of symptoms of TMD among the investigated students had been shown in Table 1. 27.7\% of the studied group had one or more symptoms of the TMD. The most common symptom was TMJ sounds (26\% of the total sample) followed by difficulty in wide opening. There was significant gender difference according to one or more symptom, with males being significantly higher than females $(\mathrm{P}<0.05)$ while insignificant gender differences were found for other symptoms of TMD (Table 1).

Table 2 shows the distribution of the young adults according to the anamnestic dysfunction index (Ai). Although mild and severe symptoms were more frequent in males $23.4 \%$ and $8 \%$ respectively than in females $16.9 \%$ and $7.4 \%$ respectively, there were insignificant gender differences in relation to anamnestic dysfunction index.

The distribution of signs of TMD among the investigated students had been shown in Table 3. $64.4 \%$ of the studied group had one or more signs of the TMD. The most common sign was pain on movement $(41.9 \%)$ followed by clicking. There was significant gender difference according to one or more sign, with females being significantly higher than males $(\mathrm{P}<0.05)$. For different signs only clicking was having significant gender differences (Table 3).

Table 4 shows the distribution of the students according to the clinical dysfunction index (Di). According to this index the percentage of the subjects decreased with increasing severity and there was no significant gender difference. 
Table 1. Frequency and relative distribution of symptoms of the TMD according to sex.

\begin{tabular}{|c|c|c|c|c|c|c|c|c|}
\hline \multirow[t]{3}{*}{ Symptoms } & & \multicolumn{5}{|c|}{ Gender } & \multirow{3}{*}{$\begin{array}{l}\text { Total } \\
\%\end{array}$} & \multirow[t]{3}{*}{$X^{2}$} \\
\hline & & \multicolumn{2}{|c|}{ Female } & \multicolumn{3}{|c|}{ Males } & & \\
\hline & & No. & $\%$ & No. & $\%$ & No. & & \\
\hline \multirow{2}{*}{ TMJ sound } & No & 418 & 76 & 322 & 71.5 & 740 & 74 & $\begin{array}{c}\mathrm{X}^{2}=2.762 \\
\mathrm{df}=1\end{array}$ \\
\hline & Yes & 132 & 24 & 128 & 28.5 & 260 & 26 & $\mathrm{P}>0.05$ \\
\hline \multirow{2}{*}{$\begin{array}{l}\text { Feeling of } \\
\text { stiffness }\end{array}$} & No & 529 & 96.2 & 423 & 94 & 952 & 95.2 & $\begin{array}{c}\mathrm{X}^{2}=0.421 \\
\mathrm{df}=1\end{array}$ \\
\hline & Yes & 21 & 3.8 & 27 & 6 & 48 & 4.8 & $\mathrm{P}>0.05$ \\
\hline \multirow{2}{*}{$\begin{array}{l}\text { Difficulty } \\
\text { in mouth } \\
\text { opening }\end{array}$} & No & 517 & 94 & 421 & 93.5 & 938 & 93.8 & $\begin{array}{c}\mathrm{X}^{2}=0.532 \\
\mathrm{df}=1\end{array}$ \\
\hline & Yes & 33 & 6 & 29 & 6.5 & 62 & 6.2 & $\mathrm{P}>0.05$ \\
\hline \multirow{2}{*}{$\begin{array}{l}\text { Pain on } \\
\text { movement }\end{array}$} & No & 531 & 96.5 & 429 & 95.3 & 960 & 96 & $\begin{array}{c}\mathrm{X}^{2}=0.316 \\
\mathrm{df}=1\end{array}$ \\
\hline & Yes & 19 & 3.5 & 21 & 4.7 & 40 & 4 & $\mathrm{P}>0.05$ \\
\hline \multirow{2}{*}{$\begin{array}{l}\text { Pain or } \\
\text { tenderness } \\
\text { on chewing }\end{array}$} & No & 537 & 97.6 & 434 & 96.4 & 971 & 97.1 & $\begin{array}{c}\mathrm{X}^{2}=0.212 \\
\mathrm{df}=1\end{array}$ \\
\hline & Yes & 13 & 2.4 & 16 & 3.6 & 29 & 2.9 & $\mathrm{P}>0.05$ \\
\hline $\begin{array}{l}\text { one or } \\
\text { more }\end{array}$ & No & 417 & 75.8 & 306 & 68 & 723 & 72.3 & $\begin{array}{c}\mathrm{X}^{2}=4.612 \\
\mathrm{df}=1\end{array}$ \\
\hline symptoms & Yes & 133 & 24.2 & 144 & 32 & 277 & 27.7 & $\mathrm{P}<0.05^{* *}$ \\
\hline
\end{tabular}

** = Significant.

Table 2. Frequency and relative distribution of students according to sex and symptoms (Ai).

\begin{tabular}{|c|c|c|c|c|c|c|}
\hline \multicolumn{7}{|c|}{ Symptom code (Ai) } \\
\hline \multirow[t]{2}{*}{ Gender } & \multicolumn{4}{|c|}{ Total } & & \multirow[t]{2}{*}{$\mathrm{X}^{2}$} \\
\hline & & $\mathrm{Ai} 0$ & AiI & AilI & & \\
\hline \multirow{2}{*}{ Females } & No. & 417 & 93 & 40 & 550 & \multirow{2}{*}{$X^{2}=3.172$} \\
\hline & $\%$ & 75.7 & 16.9 & 7.4 & 100 & \\
\hline \multirow{2}{*}{ Males } & No. & 309 & 10.5 & 36 & 450 & \multirow{2}{*}{$\begin{array}{c}\mathrm{df}=2 \\
\mathrm{P}>0.05^{*}\end{array}$} \\
\hline & $\%$ & 68.6 & 23.4 & 8 & 100 & \\
\hline \multirow{2}{*}{ Total } & No. & 726 & 198 & 76 & 1000 & \\
\hline & $\%$ & 72.6 & 19.8 & 7.6 & 100 & \\
\hline
\end{tabular}

* = Not significant; Ai0 — Complete absence of subjective symptoms; AiI—Mild symptoms; AiII—Severe symptoms of dysfunction.

The relationship between the anamnestic (Ai) and clinical dysfunction index (Di) (Table 5) shows that students who were symptom free (Ai0, 72.3\%) were found in those who had mild signs (DiI, 50.07\%) and the highest percentage of the students with mild and severe symptoms (AiI 16.3\%, AiII 11.4\%) were also found in those who had mild signs (DiI 51.53\% and 50.87\%).

Table 6 shows the association of sex and course of study with anxiety and depression as determined by HAD scale. All variants were associated significantly with the anxiety and depression.

Table 7 shows association between TMD with anxiety/depression. Out of 311 students with TMD symptoms, $206(66.23 \%)$ had signs of anxiety and depression which was statistically significant.

\section{Discussion}

TMD causes are complex and multifactorial. Numerous factors may lead to TMD. Those that may increase the risk of TMD are referred to as predispositions. Those that may lead to an onset of TMD are the initiatory, and 
Table 3. Frequency and relative distribution of the signs of the TMD according to sex.

\begin{tabular}{|c|c|c|c|c|c|c|c|c|}
\hline \multirow[t]{3}{*}{ Signs } & & \multicolumn{2}{|c|}{ Gender } & & \multicolumn{2}{|c|}{ Total } & \multicolumn{2}{|c|}{$\mathrm{X}^{2}$} \\
\hline & & \multicolumn{4}{|c|}{ Female } & \multicolumn{2}{|c|}{ Males } & \\
\hline & & No. & $\%$ & No. & $\%$ & No. & $\%$ & \\
\hline \multirow{2}{*}{ Clicking } & No & 427 & 77.6 & 346 & 76.9 & 773 & 77.3 & $X^{2}=0.023$ \\
\hline & Yes & 123 & 22.4 & 104 & 23.1 & 227 & 22.7 & $\mathrm{P}>0.05$ \\
\hline \multirow{2}{*}{ Deviation } & No & 398 & 72.4 & 333 & 74 & 731 & 73.1 & $\mathrm{X}^{2}=2.986$ \\
\hline & Yes & 152 & 27.6 & 117 & 26 & 269 & 26.9 & $\begin{array}{c}\mathrm{df}=1 \\
\mathrm{P}>0.05\end{array}$ \\
\hline \multirow{2}{*}{$\begin{array}{l}\text { Pain or } \\
\text { tenderness }\end{array}$} & No & 493 & 89.7 & 406 & 91 & 899 & 89.9 & $X^{2}=0.063$ \\
\hline & Yes & 57 & 10.3 & 44 & 9 & 101 & 10.1 & $\mathrm{P}>0.05$ \\
\hline \multirow{2}{*}{$\begin{array}{l}\text { Pain on } \\
\text { movement }\end{array}$} & No & 318 & 57.8 & 263 & 58.5 & 581 & 58.1 & $X^{2}=0.412$ \\
\hline & Yes & 232 & 42.28 & 187 & 41.5 & 419 & 41.9 & $\mathrm{P}>0.05$ \\
\hline \multirow{2}{*}{$\begin{array}{l}\text { Restricted } \\
\text { mouth } \\
\text { opening }\end{array}$} & No & 413 & 75.1 & 407 & 90.5 & 820 & 82.0 & $\begin{array}{c}X^{2}=13.63 \\
d f=1\end{array}$ \\
\hline & Yes & 137 & 24.9 & 43 & 9.5 & 180 & 18.0 & $\begin{array}{c}\mathrm{df}=\mathrm{l} \\
\mathrm{P}<0.001 * * *\end{array}$ \\
\hline \multirow{2}{*}{$\begin{array}{l}\text { one or more } \\
\text { signs }\end{array}$} & No & 169 & 30.7 & 187 & 41.6 & 356 & 35.6 & $X^{2}=4.612$ \\
\hline & Yes & 381 & 69.3 & 263 & 58.4 & 644 & 64.4 & $\begin{array}{c}\mathrm{dt}=1 \\
\mathrm{P}<0.05^{* *}\end{array}$ \\
\hline
\end{tabular}

$* *=$ Significant,$* * *=$ Highly significant.

Table 4. Frequency and relative distribution of the students according to sex and sign (Di) codes.

\begin{tabular}{|c|c|c|c|c|c|c|c|}
\hline \multicolumn{8}{|c|}{ Severity of signs (Di) } \\
\hline \multirow[t]{2}{*}{ Gender } & & \multicolumn{5}{|c|}{ Total } & \multirow[t]{2}{*}{$\mathrm{X}^{2}$} \\
\hline & & Di0 & DiI & DiII & DiIII & & \\
\hline \multirow{2}{*}{ Females } & No. & 168 & 301 & 68 & 13 & 550 & \multirow{2}{*}{$X^{2}=4.982$} \\
\hline & $\%$ & 30.5 & 54.7 & 12.3 & 2.5 & 100 & \\
\hline \multirow{2}{*}{ Males } & No. & 189 & 196 & 54 & 11 & & \multirow{4}{*}{$\begin{array}{c}\mathrm{df}=3 \\
\mathrm{P}>0.05^{*}\end{array}$} \\
\hline & $\%$ & 42 & 43.5 & 12 & 2.5 & 100 & \\
\hline \multirow{2}{*}{ Total } & No. & 357 & 497 & 122 & 24 & 1000 & \\
\hline & $\%$ & 35.7 & 49.7 & 12.2 & 2.4 & 100 & \\
\hline
\end{tabular}

$*=$ Not significant.

Table 5. Relative distribution of Ai in relation to Di among students.

\begin{tabular}{|c|c|c|c|c|c|c|c|c|}
\hline \multirow{3}{*}{ Symptoms } & \multicolumn{8}{|c|}{ Severity of signs (Di) } \\
\hline & \multicolumn{7}{|c|}{ Total } & \multirow{2}{*}{$X^{2}$} \\
\hline & & Di0 & DiI & DiII & DillI & No. & $\%$ & \\
\hline \multirow{2}{*}{ Ai0 } & No. & 298 & 362 & 63 & 00 & \multirow{2}{*}{723} & \multirow{2}{*}{72.3} & \multirow{2}{*}{$X^{2}=36.68$} \\
\hline & $\%$ & 41.21 & 50.07 & 8.72 & 00 & & & \\
\hline \multirow{2}{*}{ AiI } & No. & 40 & 84 & 38 & 1 & \multirow{2}{*}{163} & \multirow{2}{*}{16.3} & $\mathrm{df}=6$ \\
\hline & $\%$ & 24.53 & 51.53 & 23.32 & 0.62 & & & $\mathrm{P}<0.001^{* * *}$ \\
\hline \multirow{2}{*}{ AiII } & No. & 9 & 58 & 32 & 15 & \multirow{2}{*}{114} & \multirow{2}{*}{11.4} & \\
\hline & $\%$ & 7.89 & 50.87 & 28.07 & 13.16 & & & \\
\hline \multirow{2}{*}{ Total } & No. & 347 & 504 & 133 & 16 & \multirow{2}{*}{1000} & \multirow{2}{*}{100} & \\
\hline & $\%$ & 34.7 & 50.4 & 13.3 & 16.0 & & & \\
\hline
\end{tabular}

\footnotetext{
*** = Highly significant.
} 
Table 6. Association of study variables with anxiety or depression.

\begin{tabular}{|c|c|c|c|c|}
\hline \multirow[b]{2}{*}{ Variables } & \multirow[t]{2}{*}{ No anxiety or depression } & \multicolumn{2}{|c|}{ Anxiety or depression } & \multirow[b]{2}{*}{$P$ value } \\
\hline & & & & \\
\hline & $580(58.0 \%)$ & $420(42 \%)$ & & \\
\hline \multirow{2}{*}{ Sex } & Male $=450(45 \%)$ & $263(58.4 \%)$ & $187(41.6 \%)$ & \multirow{2}{*}{$\mathrm{P}<0.01 * * *$} \\
\hline & Female $=550(55 \%)$ & $317(57.6 \%)$ & $233(42.3 \%)$ & \\
\hline \multirow{5}{*}{ Course } & Medical $=178(17.8 \%)$ & $126(70.7 \%)$ & $52(29.3 \%)$ & \multirow{5}{*}{$\mathrm{P}<0.01 * * *$} \\
\hline & Dental $=310(31.0 \%)$ & $257(82.90 \%)$ & $53(17.1 \%)$ & \\
\hline & Physiotherapy $=165(16.5 \%)$ & $110(66.66 \%)$ & $55(33.34 \%)$ & \\
\hline & Pharmacy $=170(17.0 \%)$ & $105(61.76 \%)$ & $65(38.24 \%)$ & \\
\hline & Nursing $=177(17.7 \%)$ & $63(35.59 \%)$ & $114(64.41 \%)$ & \\
\hline
\end{tabular}

*** = Highly significant.

Table 7. Association between anxiety/depression and TMD.

\begin{tabular}{cccc}
\hline \multirow{2}{*}{ Anxiety or depression } & No TMD & TMD & P value \\
\cline { 2 - 4 } & $689(68.9 \%)$ & $311(31.1 \%)$ & P $<0.01^{* * *}$ \\
\hline No anxiety/depression (580) & $475(81.9 \%)$ & $105(18.1 \%)$ & $206(49 \%)$ \\
Anxiety/depression (420) & $214(51 \%)$ & \\
\hline
\end{tabular}

$* * *=$ Highly significant.

those that affect the possibility of treatment or increase its progression are referred to as prolonging factors. In some cases one and the same factor may be a predisposition, an initiating and a prolonging factor at the same time [17] [18].

The role of psychological stressors, parafunctions and behavioral processes in TMD pain has been examined in a number of studies [19].

Excessive tension can lead to constant dental clamping, which alters local circulation in muscles and ion exchange in cell membranes. These lead to accumulation of lactic and pyruvic acids, which contributes to stimulation of pain receptors [20]. A possible explanation for the association between TMD and headache is that headaches are related to muscle activity, so activity involving the head and neck is probably important in the etiology of many headaches. The presence of noise in TMJ may be due to incorrect positioning of the articular cartilage, which displaces the mandibular condyle superiorly when the mouth is opened, resulting in a click [20].

Individuals subject to stress may develop parafunctional habits and muscle tension, which lead to development of TMD [20]. Thus, parafunctional components, especially those that increase muscle tension, and changes in emotional states are good indicators of jaw pain in people with TMD, which suggests that anxiety and depression are etiological factors in TMD.

In this study the prevalence of TMD was found to be $31.1 \%$. There were studies in the literature which had found the same prevalence [21]. However, there were other studies in the literature which found high prevalence rate in same type of population [15] [22] [23]. These differences in reported TMD prevalances may be due to the characteristics of the course of study, the time when the questionnaire was administered and the characteristics of the population.

In this study there was significant sex difference concerning one symptom or more, males $32 \%$ being significantly higher than females $24.2 \%$, and female to male ratio were $1: 1.2$. These results were not consistent with the findings of earlier studies who suggest the same frequency in males and females [15] [22] [23]. Lower percentage in females comparing to males may be due to embarrassment to answer yes comparing to males because of environments in which the questions were asked without privacy.

In this study the most common self reported TMD symptom was TMJ sound (26\%) while Nomura et al. [22] 
found $65.5 \%$ patients with TMJ sound in their study.

In this study according to anamnestic index mild symptom AiI found in $23.4 \%$ of cases which was higher to the previous studies in the literature [2] [4]. our study reveals that mild symptoms $23.4 \%$ were more frequent than severe symptoms $8 \%$, this finding is consistent with other studies in the literature [21] [24] [25].

In this study there was no sex difference concerning anamnestic dysfunction index. This result is consistent with other studies [2] [23] [24]. However there are some studies in literature which found a higher incidence in females [25]. This can be explained by the reason that more females seek treatment for TMD than males [26].

In this study there was significant sex difference concerning one sign or more, females $69.3 \%$ being significantly higher than females $58.4 \%$. These results are consistent with the previous studies in the literature [5] [22] [24] [25]. The most common sign in this study was pain on movement (41.9\%) while in other similar studies in literature clicking was the most common sign [27].

In this study according to this clinical dysfunction index the percentage of the subjects decreased with increasing severity and there was no significant gender difference. These results tend to be close to other studies. [14] [28]

A highly significant relationship between anamnestic and clinical dysfunction index was found in this study. The majority of subjects with symptom free, mild and severe symptoms had mild clinical signs.

In this study HAD showed that $42 \%$ of the students had anxiety or depression. There are other studies in the literature which are comparable to our study [29], but Inam et al. found a higher prevalence of anxiety and depression in their study $(60 \%)[30]$.

In this study we found that TMD was significantly associated with anxiety and depression (66.2\%) which is in consistent with other studies in literature [15] [30] [31].

\section{Conclusion}

Our study shows significant association between emotional stress and symptoms of TMD but not clinical sign and this will support many theories of relating this to psychological cause. Thus, greater understanding of this condition among populations exposed to high levels of emotional stress such as students is of considerable importance so that we can motivate the affected students to seek proper treatment.

\section{References}

[1] Okeson, J.P. (2003) Treatment of Temporomandibular Joint Disorders. In: Management of Temporomandibular Disorders and Occlusion, 5th Edition, Mosby, St. Louis, 413-435.

[2] Kalanzi, D., Osman, Y.I. and Shaikh, A. (2005) Prevalence of Sign and Symptoms of the Temporomandibular Join Dysfunctions in Subjects with Different Occlusion Using Helkimo Index. Thesis for Degree of Masterscience in Restorative Dentistry, University of Western Cape, Cape Town.

[3] De Boever, J.A. and Adriaens, P.A. (1983) Occlusal Relationship in Patients with Pain-Dysfunction Symptoms in the Temporomandibular Joints. Journal of Oral Rehabilitation, 10, 1-7. http://dx.doi.org/10.1111/j.1365-2842.1983.tb00093.x

[4] Hiltunen, K., Schmidt-Kaunisaho, K., Nevalainen, J., Närhi, T. and Ainamo, A. (1995) Prevalence of Signs of Temporomandibular Disorders among Elderly Inhabitants of Helsinki, Finland. Acta Odontologica Scandinavica, 53, 20-23. http://dx.doi.org/10.3109/00016359509005939

[5] Magnusson, T., Egermarki, I. and Carlsson, G.E. (2005) A Prospective Investigation over Two Decades on Signs and Symptoms of Temporomandibular Disorders and Associated Variables. A Final Summary. Acta Odontologica Scandinavica, 63, 99-109.

[6] Helkimo, M. (1976) Epidemiological Surveys of Dysfunction of the Masticatory System. Oral Science Review, 7, 5469.

[7] Suma, S. and Veerendra Kumar, B. (2012) Temporomandibular Disorders and Functional Somatic Syndromes: Deliberations for the Dentist. Indian Journal of Dental Research, 23, 529-536. http://dx.doi.org/10.4103/0970-9290.104965

[8] Graber, T.M., Rakosi, T. and Petrovic, A.G. (2009) Functional Analysis-Examination of Temporomandibular Joint and Condylar Movement. In: Dentofacial Orthopedics with Functional Appliances, 2nd Edition, Mosby, St. Louis, 135-140.

[9] Athanasiou, A.E. (2003) Orthodontics and Craniomandibular Disorders. In: Samire, B., Ed., Textbook of Orthodontics, 2nd Edition, Saunders, Philadelphia, 478-493.

[10] Egermark-Eriksson, I., Carlsson, G.E. and Magnusson, T. (1987) A Long-Term Epidemiologic Study of the Relation- 
ship between Occlusal Factors and Mandibular Dysfunction in Children and Adolescents. Journal of Dental Research, 66, 67-71. http://dx.doi.org/10.1177/00220345870660011501

[11] Shiau, Y.Y. and Chang, C. (1992) An Epidemiological Study of Temporomandibular Disorders in University Students of Taiwan. Community Dentistry and Oral Epidemiology, 20, 43-47. http://dx.doi.org/10.1111/j.1600-0528.1992.tb00672.x

[12] Jagger, R.G. and Wood, C. (1992) Signs and Symptoms of Temporomandibular Joint Dysfunction in a Saudi Arabian Population. Journal of Oral Rehabilitation, 19, 353-359. http://dx.doi.org/10.1111/j.1365-2842.1992.tb01577.x

[13] Droukas, B., Lindée, C. and Carlsson, G.E. (1984) Relationship between Occlusal Factors and Signs and Symptoms of Mandibular Dysfunction: A Clinical Study of 48 Dental Students. Acta Odontologica Scandinavica, 42, $277-283$. http://dx.doi.org/10.3109/00016358408993881

[14] Helkimo, M. (1974) Studies on Function and Dysfunction of the Masticatory System, II: Index for Anamnestic and Clinical Dysfunction and Occlusal State. Svensk Tandlakare Tidskrift, 67, 101-121.

[15] Bonjardim, L.R., Lopes-Filho, R.J., Amado, G., Albuquerque Jr., R.L. and Goncalves, S.R. (2009) Association between Symptoms of Temporomandibular Disorders and Gender, Morphological Occlusion, and Psychological Factors in a Group of University Students. Indian Journal of Dental Research, 20, 190-194. http://dx.doi.org/10.4103/0970-9290.52901

[16] Mykletun, A., Stordal, E. and Dahl, A.A. (2001) Hospital Anxiety and Depression (HAD) Scale: Factor Structure, Item Analyses and Internal Consistency in a Large Population. The British Journal of Psychiatry, 179, 540-544. http://dx.doi.org/10.1192/bjp.179.6.540

[17] McNaill, C., Danzing, D., Farrar, W., Gelb, H., Lerman, M.D., Moffett, B.C., Pertes, R., Solberg, W.K. and Weinberg, L.A. (1980) Craniomandibular (TMJ) Disorders-The State of the Art. Journal of Prosthetic Dentistry, 44, 434-437. http://dx.doi.org/10.1016/0022-3913(80)90104-3

[18] Okeson, J. (1996) Orofacial Pain: Guidelines for Classification, Assessment, and Management. 3rd Edition, Quintessence Publishing, Chicago, 119-120.

[19] Uhac, I., Kovac, Z., Valentic-Peruzovic, M., Juretic, M., Moro, L.J. and Grzic, R. (2003) The Influence of War Stress on the Prevalence of Signs and Symptoms of Temporomandibular Disorders. Journal of Oral Rehabilitation, 30, 211217. http://dx.doi.org/10.1046/j.1365-2842.2003.01030.x

[20] Poveda-Roda, R., Bagán, J.V., Díaz Fernández, J.M., Bazán, S.H. and Soriano, Y.J. (2007) Review of Temporomandibular Joint Pathology. Part I: Classification, Epidemiology and Risk Factors. Medicina Oral Patologia Oral y Cirugia Bucal, 12, E292-E298.

[21] Otuyemi, O.D., Owotade, F.J., Ugboko, V.I., Ndukwe, K.C. and Olusile, O.A. (2000) Prevalence of Signs and Symptoms of Temporomandibular Disorders in Young Nigerian Adults. Journal of Orthodontics, 27, 61-65. http://dx.doi.org/10.1093/ortho/27.1.61

[22] Nomura, K., Vitti, M., Oliveira, A.S., Chaves, T.C., Semprini, M., Siéssere, S., et al. (2007) Use of the Fonseca's Questionnaire to Assess the Prevalence and Severity of Temporomandibular Disorders in Brazilian Dental Undergraduates. Brazilian Dental Journal, 18, 163-167. http://dx.doi.org/10.1590/S0103-64402007000200015

[23] De Oliveira, A.S., Dias, E.M., Contato, R.G. and Berzin, F. (2006) Prevalence Study of Signs and Symptoms of Temporomandibular Disorder in Brazilian College Students. Brazilian Oral Research, 20, 3-7. http://dx.doi.org/10.1590/S1806-83242006000100002

[24] Abdulla, B.A. and Hussein, S.M. (1992) Temporomandibular Disorders among a Sample of Mosul University Students. Master's Thesis, College of Dentistry, University of Baghdad, Baghdad.

[25] De Kanter, R.J., Truin, G.J., Burgersdijk, R.C., Van’t Hop, M.A., Battistuzzi, P.G., Kalsbeek, H. and Käyser, A.F. (1993) Prevalence in the Dutch Adult Population and a Meta-Analysis of Signs and Symptoms of Temporomandibular Disorder. Journal of Dental Research, 72, 1509-1518. http://dx.doi.org/10.1177/00220345930720110901

[26] McNeill, C. (1997) Management of Temporomandibular Disorders: Concept and Controversies. The Journal of Prosthetic Dentistry, 77, 510-522. http://dx.doi.org/10.1016/S0022-3913(97)70145-8

[27] Elfving, L., Helkimo, M. and Magnusson, T. (2002) Prevalence of Different Temporomandibular Joint Sounds, with Emphasis on Disc-Displacement, in Patients with Temporomandibular Disorders and Controls. Swedish Dental Journal, 26, 9-19.

[28] Pow, E.H., Leung, K.C. and McMillan, A.S. (2001) Prevalence of Symptoms Associated with Temporomandibular Disorders in Hong Kong Chinese. Journal of Orofacial Pain, 5, 228-234.

[29] Jadoon, N.A., Yaqoob, R., Raza, A., Shehzad, M.A. and Zeshan, S.C. (2010) Anxiety and Depression among Medical Students: A Cross-Sectional Study. Journal of Pakistan Medical Association, 60, 699-702.

[30] Inam, S.N., Saqib, A. and Alam, E. (2003) Prevalence of Anxiety and Depression among Medical Students of Private 
University. Journal of Pakistan Medical Association, 53, 44-47.

[31] Minghelli, B., Morgado, M. and Caro, T. (2014) Association of Temporomandibular Disorder Symptoms with Anxiety and Depression in Portuguese College Students. Journal of Oral Science, 56, 127-133.

http://dx.doi.org/10.2334/josnusd.56.127 